Article

\title{
Environmental Performances of a Cubic Modular Steel Structure: A Solution for a Sustainable Development in the Construction Sector
}

\author{
Sebastian George Maxineasa *(D), Dorina Nicolina Isopescu *D, Ioana-Roxana Baciu (D) and Marius Lucian Lupu (D) \\ Department of Civil and Industrial Engineering, Faculty of Civil Engineering and Building Services, \\ "Gheorghe Asachi" Technical University of Iasi, 700050 Iasi, Romania; ioanaroxana.baciu@yahoo.com (I.-R.B.); \\ mariuslucianlupu@gmail.com (M.L.L.) \\ * Correspondence: sebastian.maxineasa@tuiasi.ro (S.G.M.); dorina_isopescu@yahoo.co.uk (D.N.I.)
}

Citation: Maxineasa, S.G.; Isopescu, D.N.; Baciu, I.-R.; Lupu, M.L. Environmental Performances of a Cubic Modular Steel Structure: A Solution for a Sustainable Development in the Construction Sector. Sustainability 2021, 13, 12062. https://doi.org/10.3390/su132112062

Academic Editor: Oleg Kapliński

Received: 8 September 2021

Accepted: 29 October 2021

Published: 1 November 2021

Publisher's Note: MDPI stays neutral with regard to jurisdictional claims in published maps and institutional affiliations.

Copyright: (c) 2021 by the authors. Licensee MDPI, Basel, Switzerland. This article is an open access article distributed under the terms and conditions of the Creative Commons Attribution (CC BY) license (https:// creativecommons.org/licenses/by/ $4.0 /)$.

\begin{abstract}
The production of building materials is a significant component of the impact the construction sector has on the natural environment. Steel is among the most utilized materials, having various applications specific to the built environment. Therefore, understanding the impact of this structural material represents an important step in achieving global sustainable development. The paper aims to analyze the effects of different steel structural elements on the Earth's ecosystem with respect to concerns over sustainability. In order to reach this goal, the authors have analyzed a dwelling steel structure based on cubic modules with high structural modularity. In addition, the study looks at the influence of an over the floor reinforced concrete slab in order to gain an overall view regarding environmental performances. The impact on the natural environment has been analyzed by considering the cradle-to gate with options Life Cycle Assessment study. The paper provides up-to-date knowledge on the environmental performances of the analyzed structure, presenting encouraging conclusions for construction sector specialists with respect to the use of steel as a material that can represent a solution in the current global effort to minimize the environmental burdens imposed by the construction sector.
\end{abstract}

Keywords: natural environment; construction sector; steel; sustainable development; cradle-to-gate with options; Life Cycle Assessment

\section{Introduction}

It is well-known that the impact on the natural environment resulting from people's daily activities is constantly increasing every year and that this impact threatens to limit the abilities of future generations to ensure proper development. At the global scale, this negative influence is characterised by an alarming increase in the amount of greenhouse gas emissions into the atmosphere, as well as the quantity of non-renewable energy consumed in order to satisfy living standards. In order to have a complete view of the present negative situation regarding the natural environment, we need to take into consideration, too, the distressing rates of raw material consumption at the global scale. The latest report of the Global Footprint Network shows that globally we are consuming approximately $70 \%$ more raw materials than Earth has the capacity to naturally renew [1]. Therefore, understanding and taking steps to achieve sustainability is the most significant challenge that must be faced in the near future by all global industrial sectors, with the goal of drastically reducing their environmental burdens.

It is common knowledge that the building sector is responsible for one of the most substantial impacts on the natural environment. The construction industry is responsible for the consumption of approximately $60 \%$ of the entire volume of natural resources consumed at the global scale. Furthermore, the construction industry is responsible for consuming nearly $40 \%$ of the global amount of energy produced, generating at the same 
time approximately $25 \%$ of the total global waste and over $40 \%$ of the overall volume of greenhouse gases emitted into the atmosphere. Another critical environmental effect of the sector is represented by the amount of building materials consumed, which is more than half of the volume of materials used globally [2-15].

Even though the last decades have seen the adoption of different rules and regulations (e.g., the enforcement of the Nearly Zero Energy Buildings regulation in the European Union) intended to reduce non-renewable energy consumption in building work, as well as in minimizing carbon dioxide emissions, the construction sector remains one of the biggest polluters globally. It must be clearly understood that an important part of the total impact of the construction sector is influenced in a substantial manner by the amount and type of materials employed for maintaining the state of the existing built environment and, most importantly, for creating new buildings.

Thus, taking into account the fact that the world's population is significantly increasing, it is expected that in the near future the consumption of construction materials will increase due to the need for enlarging the existing built environment. Taking this into account, it can with justification be said that besides improving energy efficiency standards in the construction sector, we also need to improve the types and amounts of materials consumed in this sector. The negative effects resulting from the use of massive volumes of materials can be reduced by finding different solutions and/or materials that can be used in building design (e.g., by considering structural systems which can be disassembled, or by using various highly recyclable structural materials). Therefore, fully evaluating and understanding the impact of various construction materials and applying that knowledge to the choice of products used in this sector will have a major influence on the global sustainable development of the built environment [4-7,16-25].

Steel is considered to be one of the principal materials used in the construction sector. Whether it is used as bars in reinforced concrete elements, as connectors or fixing elements for timber structures, or as structural steel sections, this material is consumed in huge amounts in construction. From this perspective, it must be mentioned that the material's specific manufacturing processes are responsible for about $9 \%$ of the overall volume of carbon dioxide $\left(\mathrm{CO}_{2}\right)$ emitted worldwide $[5,26]$.

At the global scale, in the last four decades, the quantity of steel manufactured has increased by approximately 2.6 times, reaching 1600 million tons in 2013 [5,27]. The global consumption of this material is rapidly increasing year after year; the value registered for steel consumption in 2017 is approximately 0.2 billion tons higher than the one reported in 2013 [28,29]. Taking into account that approximately half of the total amount of steel fabricated worldwide is consumed in processes specific to the built environment, consideration of the ecological effects of this material in the construction sector is highly consequential $[5,26]$.

Part of the impact on the natural environment associated with steel-based products is due to the methods employed for manufacturing the component material. Most commonly, steel is produced using the electric arc furnace (EAF) method or the basic oxygen furnace (BOF) method [5,30-33]. The EAF technique consumes electricity, while the BOF production method uses substantial amounts of natural gas and coal. It should be noted that in the former method, large quantities of scrap materials are consumed; it can therefore be said that EAF products have a smaller negative ecological impact $[5,34]$.

Compared with other traditional building materials, steel has a unique ecological characteristic. It is a material that can be fully recycled numerous times without diminishment of its mechanical properties [5,31,32]. Steel producers have taken serious steps to minimize the ecological impact of their products. One visible result of these environmental policies has been observed in the United States of America, where the carbon footprint of steel production is $47 \%$ lower than what it was in 1990 [5,34].

Considering the above, and also taking into account that the ecological effects of the built environment are expected to increase, civil engineering specialists must seek to put into effect measures that will significantly reduce the environmental burdens specific 
to the construction industry. Furthermore, as previously mentioned, this sector exerts a considerable influence over the ecological impact of the steel manufacturing industry; therefore, the use of this material in the built environment should involve an understanding of the effects on the Earth's ecosystem and efforts to diminish them.

Seeing that, in recent years, different norms and European directives have been promoted with the declared goal of significantly reducing energy consumption while creating optimal interior living conditions during the usage phase of a construction, the authors believe that at the present moment it is of paramount importance to fully understand and improve the environmental performance of the structural materials used in building construction. Therefore, the goal of the present paper is to determine the environmental consequences of using steel as a structural material. This aim is achieved by analysing a dwelling structure using cubic modules made of steel square hollow sections (SHS). The environmental burdens this structure imposes were determined and interpreted by employing the Life Cycle Assessment (LCA) methodology.

\section{Case Studies}

The objective of the study was achieved by using the international standards ISO 14040:2006 and ISO 14044:2006, which define LCA as the "compilation and evaluation of the inputs, outputs and the potential environmental impacts of a product system throughout its life cycle" $[35,36]$. In the present study, the authors have considered the cradle-to-gate with options LCA study in order to assess the impact on the environment of the analyzed structure. In order to enable a better understanding of the boundaries of the study, Table 1 presents the life cycle stages that have been used. These modules have been characterized using the European standards EN 15978:2011 [37] and EN 15804+A1:2013 [38].

Table 1. Life cycle phases considered.

\begin{tabular}{cc}
\hline Life Cycle Phase & Life Cycle Module \\
\hline Extraction of raw materials & A1 \\
Processing of raw materials and production of construction materials & A3 \\
De-construction/Demolition & C1 \\
Waste processing & C3 \\
Reuse/Recycling of materials & D \\
Transportation phases & A2, A4, C2 \\
\hline
\end{tabular}

The authors have considered the above-mentioned type of LCA study due to the fact that no type of maintenance work is required during the operation stage (e.g., reapplying a protective coating), seeing as the steel elements will be extremely well-protected against moisture in a highly energy-efficient building. This protection is a direct result of the different construction details, materials and technologies (e.g., vapour barrier foil, a thick layer of thermal insulating material, indoor heat recovery ventilation system) that have to be used in order to achieve a building with a low level of energy consumption that is able to create and maintain optimal indoor climate conditions. Therefore, the present study has some limitations regarding the life cycle modules considered in the assessment. The authors haven't considered all the modules for several reasons. For one, module A5 has not been taken into account due to the fact that the existing databases are not clear on the impact resulting from different technologies and machines used in the installation process. Therefore, in order to avoid influencing the final results and deriving invalid conclusions, the authors decided to not consider this module. As stated before, according to the EU regulations on energy consumption for heating and cooling, the levels of energy used are going to be significantly reduced, and therefore we think that the main environmental problem for the construction sector will be the negative impact resulting from the use of different materials. This is the reason we have not considered module B6. Additionally, taking into account the nZEB regulations, of the final amount of operational energy consumed, a substantial part should come from renewable sources, and the values for heating 
and cooling will be comparable in many EU countries. Thus, in the future, in many EU countries the impact resulting from energy use during the usage stage of a building should be at least similar, depending on the regulations adopted by each country. As stated before, the authors are only interested in evaluating the ecological influence of the materials that are used for realizing the analyzed structural system.

The analyzed single floor dwelling is formed by using nine cubic modules, as presented in Figure 1. A single steel unit has a length and a height equal to $3.6 \mathrm{~m}$. The vertical and horizontal structural elements of the module are made from square hollow section (SHS) profiles, $180 \mathrm{~mm}$ in depth and width, and with a specified thickness of $12 \mathrm{~mm}$ (Figure 2). The structural behaviour of the cubic modules has been analyzed for different structural configurations in a study conducted at the Faculty of Civil Engineering and Building Services of Iasi [39]. The thermal performances of a structure made of steel cubic modules with similar characteristics are presented in Isopescu et al. [40].

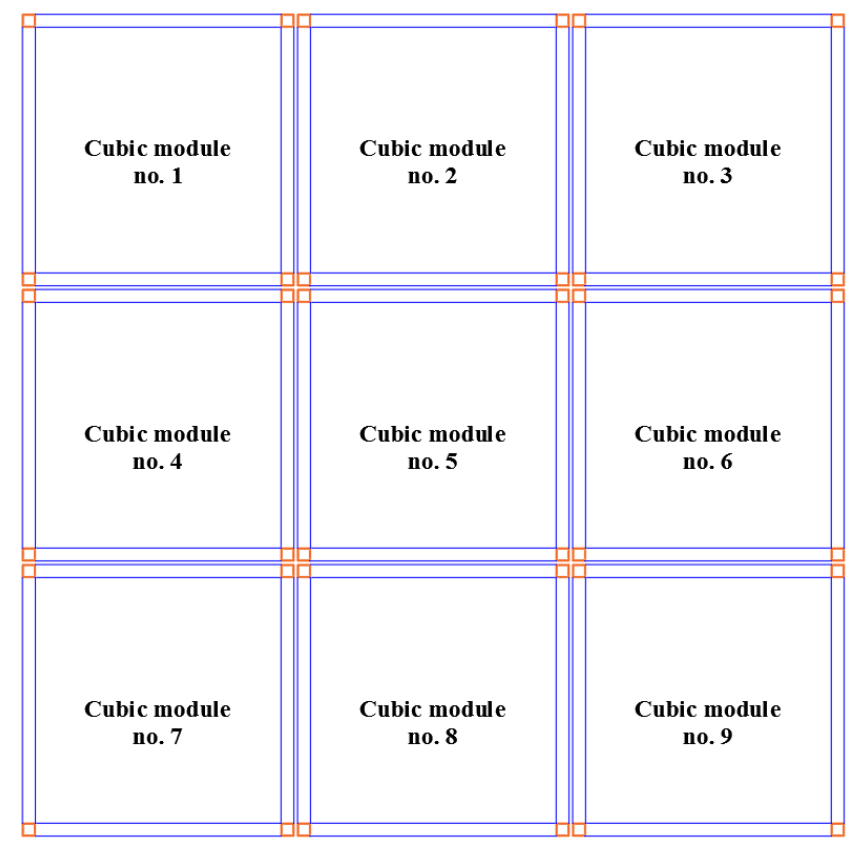

Figure 1. The in-plan configuration of the analyzed structures.

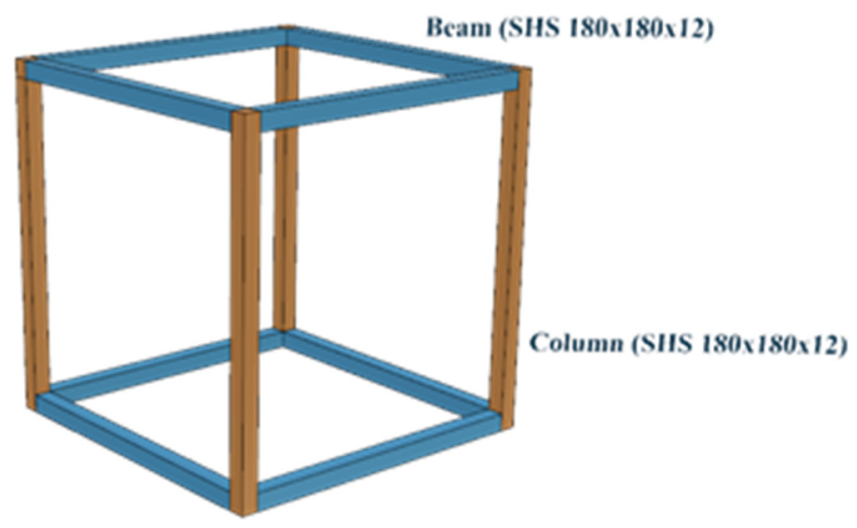

Figure 2. Steel cubic module.

Taking into account that the aim of the study is to determine the environmental implications of using steel as a structural material, the performed analysis only considers the beams, columns, and connection components. The authors have also evaluated the ecological burdens of an over the floor reinforced concrete slab, which has a height of 
$17 \mathrm{~cm}$. The composite floor is made of C 20/25 concrete and a steel deck with a thickness of $1 \mathrm{~mm}$. All structural elements have been designed by considering the European codes and national standards. As a final step of the assessment, the environmental performances of the steel structure were compared with those of the reinforced concrete slab. In order to provide a clear view regarding the cubic module and the quantities of components used for assembling the structure, Figure 3 shows the two types of junctions between the linear steel elements.
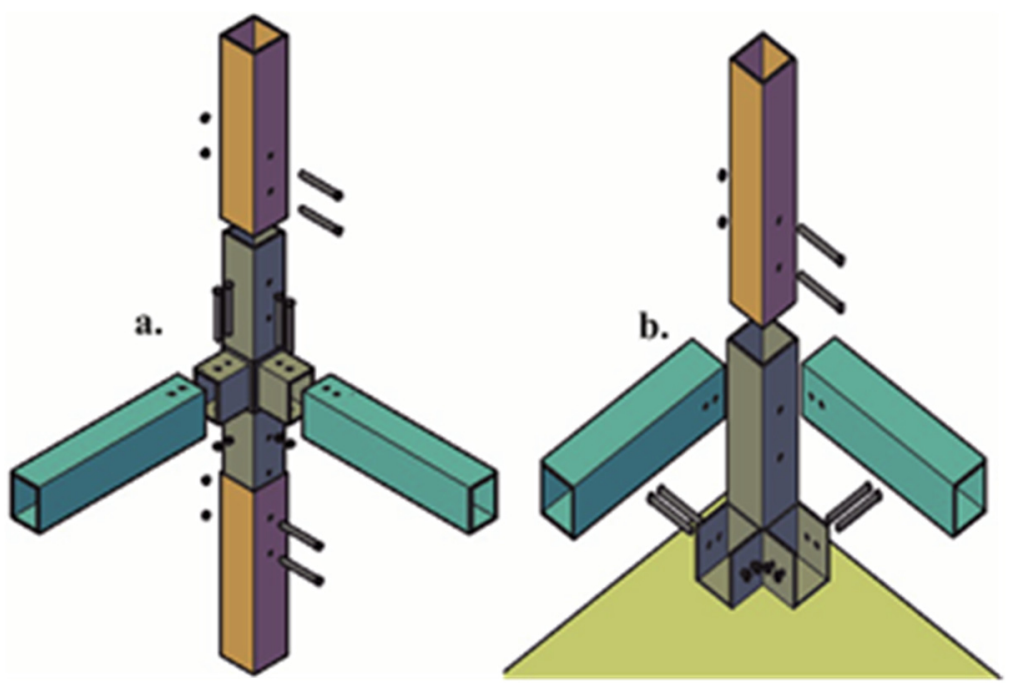

Figure 3. (a) Joint between columns and beams. (b) Joint between columns and ground floor. Source: $[39,40]$.

So as to include the influence of the transportation phases along with the environmental influence of the analyzed elements, a diesel truck with a Euro 6 engine and a payload capacity of 3.3 tons has been considered during the study. Table 2 displays the transport distances that have been used in the assessment. All transport distances have been considered, as they were identified on a real case at the local scale.

Table 2. Transportation distances.

\begin{tabular}{ccc}
\hline Material & Distances $\mathbf{( k m )}$ & From $\rightarrow$ To \\
\hline SHS steel profiles & 10 & Steel mill $\rightarrow$ construction site \\
Steel screws & 10 & Steel mill $\rightarrow$ construction site \\
Steel deck & 10 & Steel mill $\rightarrow$ construction site \\
Steel reinforcement & 10 & Steel mill $\rightarrow$ construction site \\
Fine aggregate & 30 & Quarry $\rightarrow$ concrete mixing plant \\
Coarse aggregate & 30 & Quarry $\rightarrow$ concrete mixing plant \\
Cement CEM I 32.5 & 165 & Quarry $\rightarrow$ concrete mixing plant \\
Concrete & 25 & Concrete mixing plant $\rightarrow$ construction site \\
Scrap steel & 10 & Construction site $\rightarrow$ recycling unit \\
Recycled concrete & 30 & Construction site $\rightarrow$ concrete mixing plant \\
\hline
\end{tabular}

Table 3 shows the impact categories that have been considered for assessing the effects of the considered products over the natural environment. The environmental impact indicators used for performing the analysis were selected by considering the recommendations of the European Commission's Joint Research Centre-Institute for Environment and Sustainability [41]. Additionally, the assessment incorporates the act L124 2013/179/EU [42] and the European norm EN 15804+A1:2013 [38]. In order to determine the ecological effects of the assessed products, the midpoint approach and the $\mathrm{GaBi}$ ts software have been utilised, using the software's database. 
Table 3. Environmental impact indicators considered.

\begin{tabular}{ccc}
\hline Impact Category & Parameter & Unit \\
\hline $\begin{array}{c}\text { Global Warming (Climate Change) } \\
\text { (including biogenic carbon) }\end{array}$ & $\begin{array}{c}\text { Radiative forcing global } \\
\text { warming potential (GWP) }\end{array}$ & kg CO -eq. \\
Human Toxicity (cancer effects) & $\begin{array}{c}\text { Human toxicity potential, } \\
\text { cancer effects (HTPc) } \\
\text { Depletion potential of the } \\
\text { stratospheric ozone } \\
\text { Ozone Depletion }\end{array}$ & CTUh \\
& $\begin{array}{c}\text { layer/Ozone depletion } \\
\text { potential (ODP) }\end{array}$ & kg CFC-11 eq. \\
\hline
\end{tabular}

\section{Analysing the Environmental Impact from the Cradle-to-Gate Perspective}

The first phase of the analysis consists in determining the ecological burdens of the pre-operation phase of the steel cubic modules that form the considered dwelling structure. Therefore, the A1, A2, A3, and A4 life cycle modules have been considered at this stage of the study. Table 4 displays the amount of component materials that were considered in determining the impact of the construction products. Even if the columns and beams are made from SHS profiles with the same characteristics, the authors decided to evaluate the impact of these linear structural elements separately (i.e., the impact of beams and the impact of columns), with the goal of gaining a better comprehension regarding the obtained results. The pre-operation ecological impact of the reinforced concrete slab has been determined by considering the amounts of component materials presented in Table 5 .

Table 4. The quantities of materials used in the steel structure analyzed.

\begin{tabular}{cc}
\hline Component Material & Quantity (kg) \\
\hline SHS steel profiles-Columns & 8048.16 \\
SHS steel profiles-Beams & $16,096.32$ \\
Steel screws & 601.34 \\
\hline
\end{tabular}

Table 5. The quantities of component materials used in the analysis of the reinforced concrete slab.

\begin{tabular}{cc}
\hline Component Material & Quantity (kg) \\
\hline Fine aggregate & 18,495 \\
Coarse aggregate & 18,495 \\
Cement (CEM I 32.5) & 7471 \\
Water & 3736 \\
Steel reinforcement & 2376.20 \\
Steel deck (steel sheet) & 2376.20 \\
\hline
\end{tabular}

The values describing the implications for the natural environment resulting from the use of steel cubic modules for the construction of the analyzed structure are presented in Figure 4 . These results show that the beams have the greatest negative influence, while the SHS steel profiles used for columns have a carbon footprint that is almost 2.5 times larger than that of the fixing elements. Compared to all the analyzed steel products, the amount of diesel and the transportation phase have an insignificant impact on the GWP parameter. 


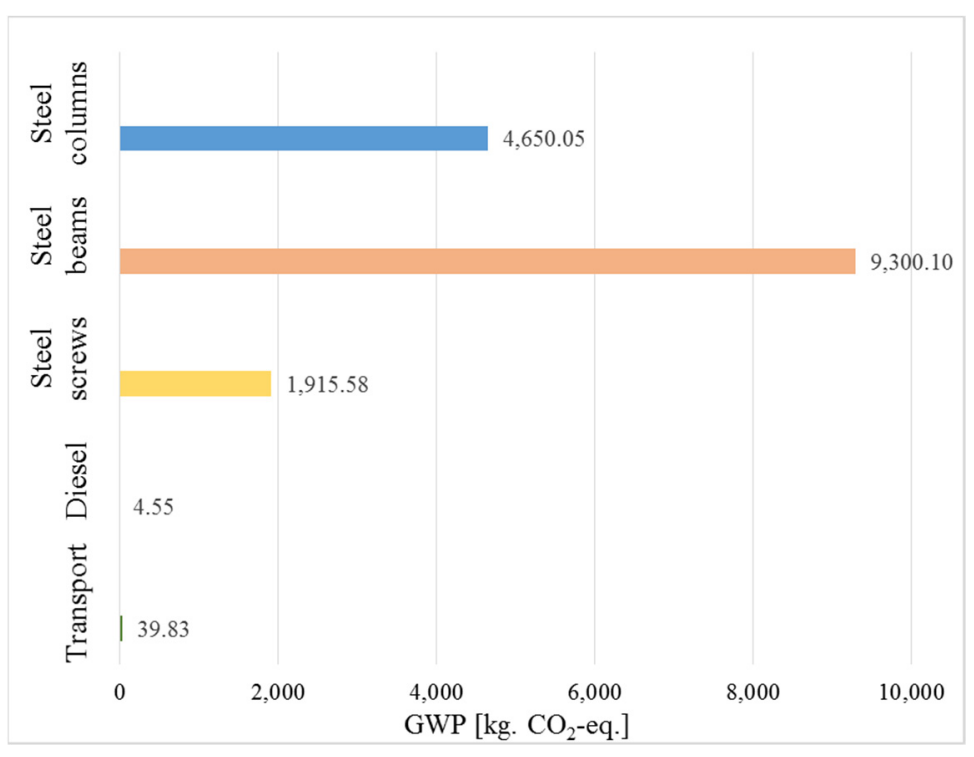

Figure 4. Cradle-to-gate impact of the steel structure for the Global Warming indicator.

In the case of the HTPc environmental parameter (Figure 5), the steel beams have the most notable impact. The steel columns have the second greatest negative effect, followed by the impact exerted by the steel screws, the amount of diesel used, and, finally, the transportation phase. The results for the Ozone Depletion environmental indicator are presented in Figure 6. As in the case of the two previously analyzed environmental parameters, the beams have the most important impact over the stratospheric ozone layer, followed by the negative effects of the columns, screws, and the amount of diesel consumed in the transportation phase.

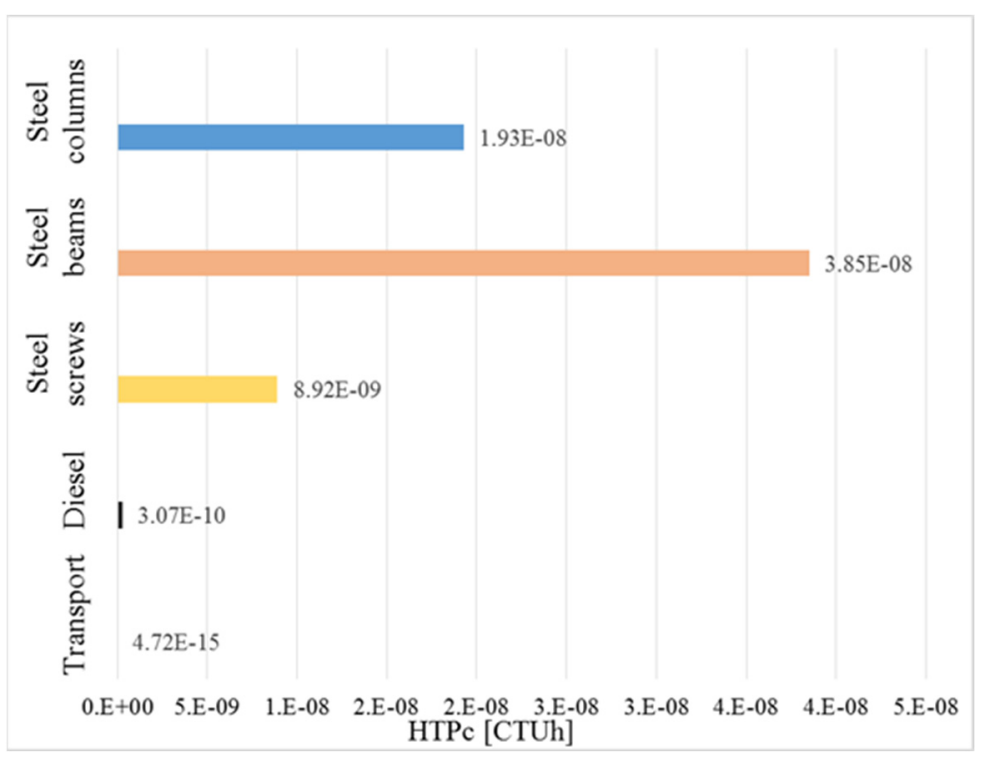

Figure 5. Cradle-to-gate impact of the steel structure for the Human Toxicity indicator. 


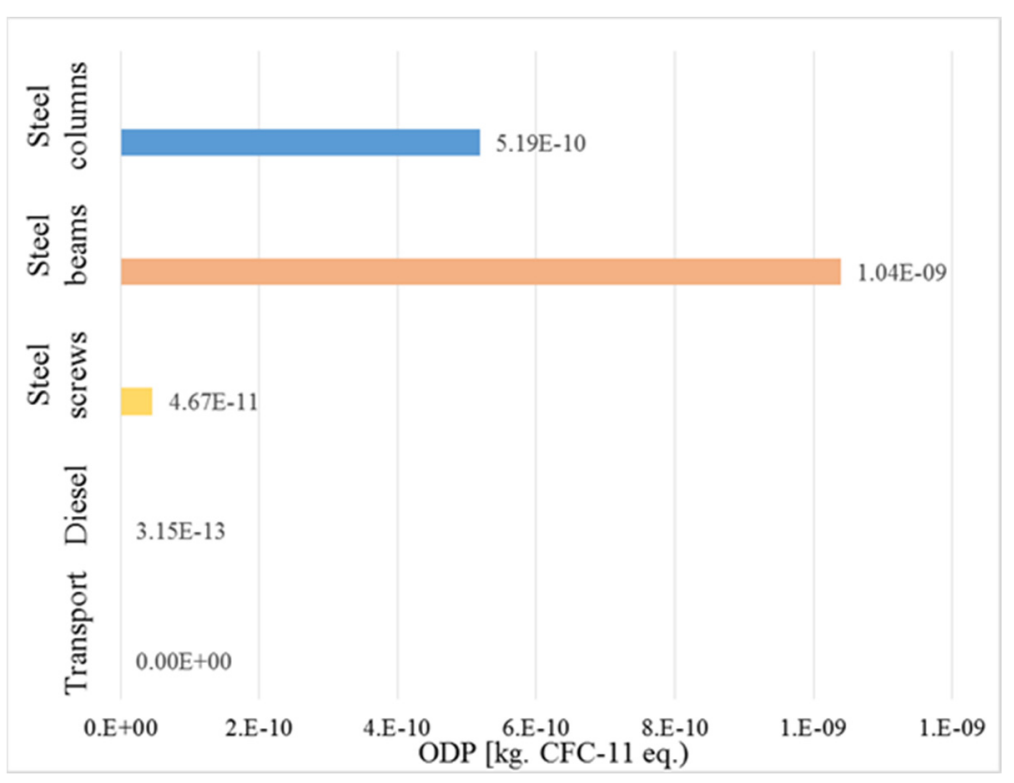

Figure 6. Cradle-to-gate impact of the steel structure for the Ozone Depletion indicator.

The values that describe the impact of the product under analysis over the preoperation stage are presented in Figures 7-9. The impact of the reinforced concrete slab for the GWP parameter is described in Figure 7. It can be noticed that the negative effect of cement represents approximately $84 \%$ of the combined impact of the steel deck and steel reinforcements. Additionally, the three above mentioned component materials are responsible for nearly the entire carbon footprint of the reinforced concrete slab.

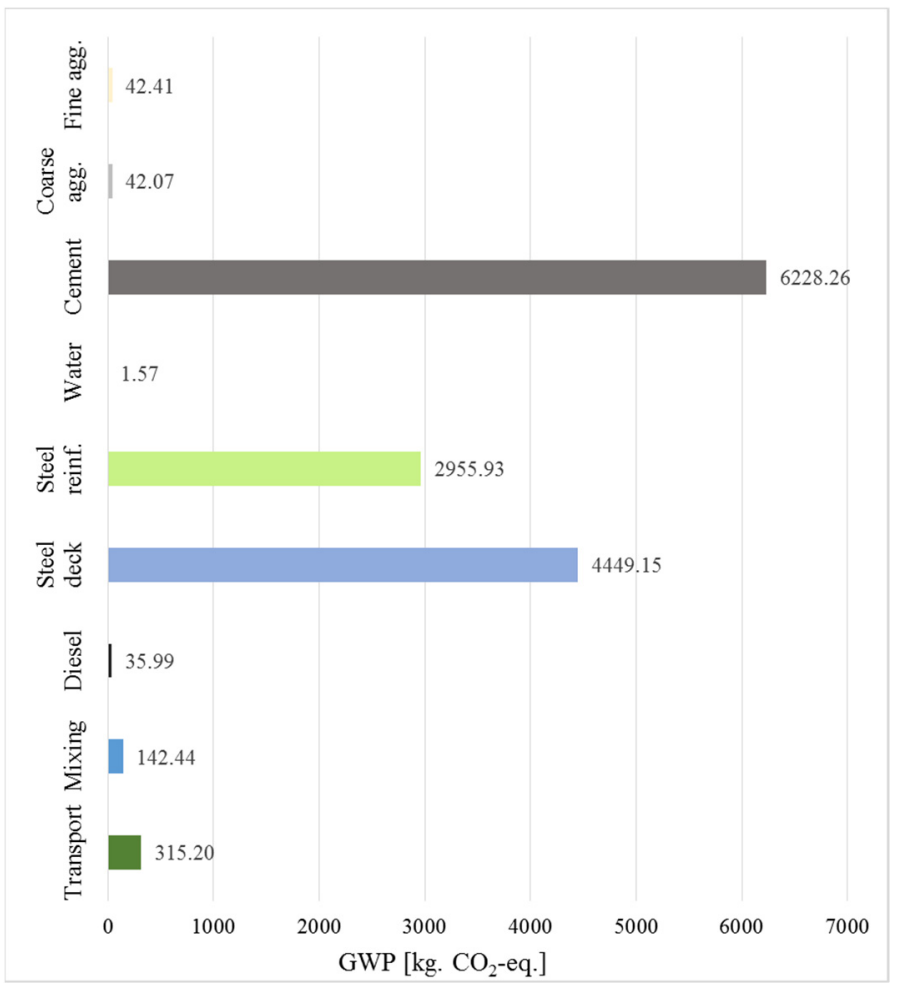

Figure 7. Cradle-to-gate impact of the concrete slab for the Global Warming indicator. 


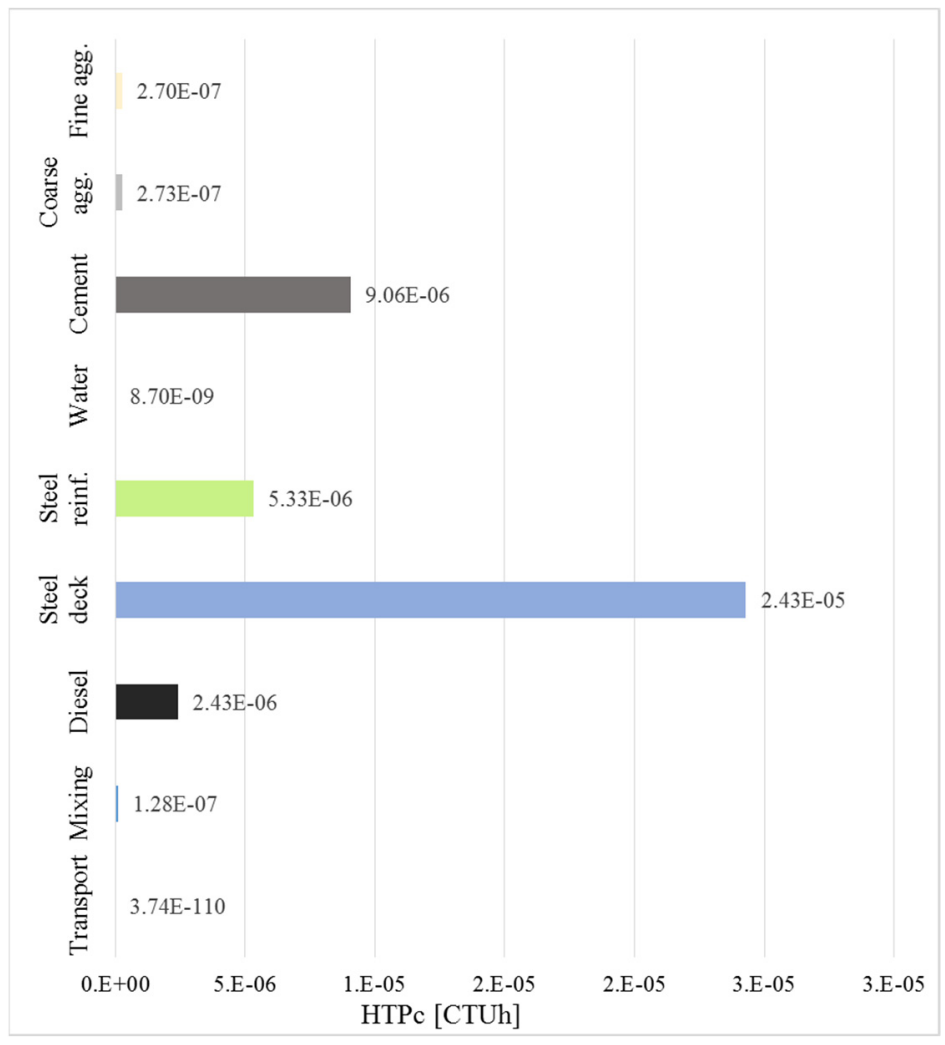

Figure 8. Cradle-to-gate impact of the concrete slab for the Human Toxicity indicator.

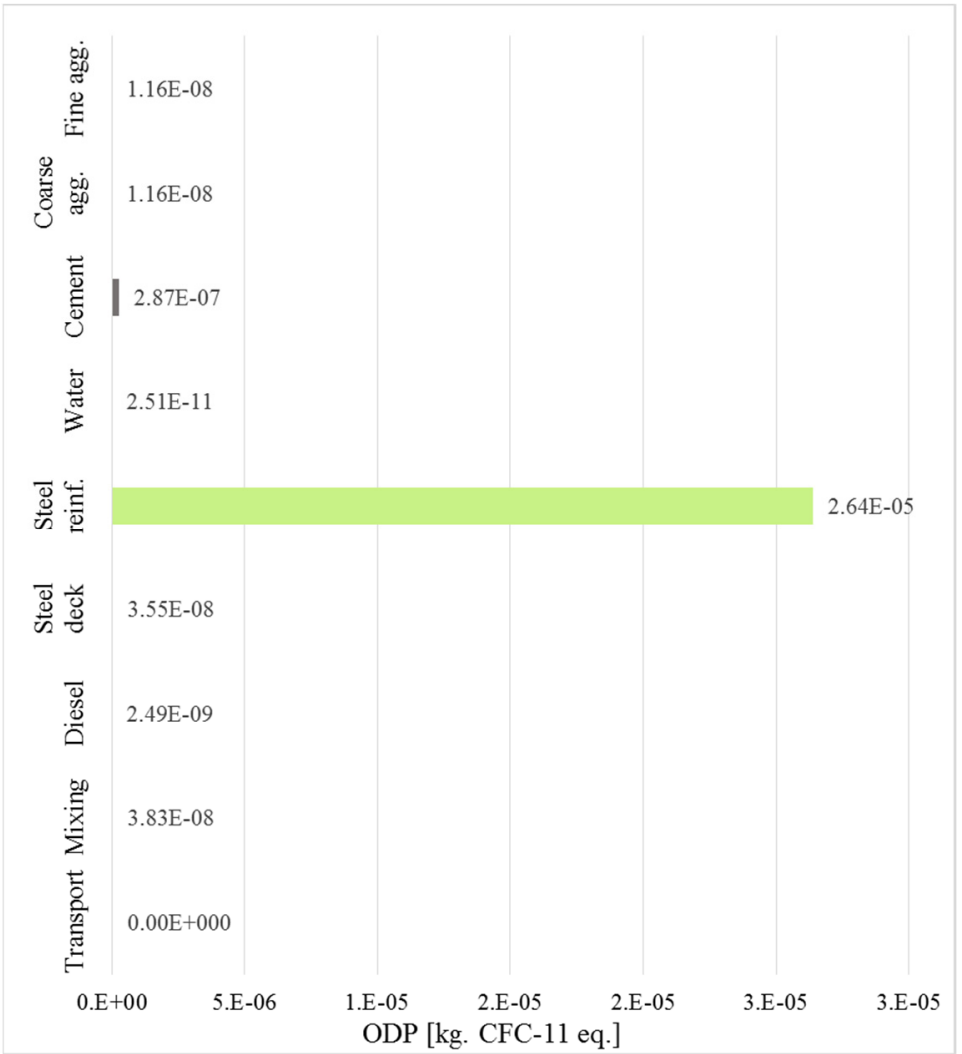

Figure 9. Cradle-to-gate impact of the concrete slab for the Ozone Depletion indicator. 
In Figure 8, it can be seen that the overall value for the HTPc parameter is highly influenced by the steel deck, this product being responsible for more than $50 \%$ of the total cancerous effects. As represented by the results, the cement, steel reinforcement, and diesel have an important impact on the overall result as well. Figure 9 presents the environmental effects of the analyzed construction product in the case of the ODP impact indicator. In this case, the amount of steel reinforcement makes up for about $99 \%$ of the overall negative impact on the stratospheric ozone layer.

Comparing the values for the cradle-to-gate evaluation (Table 6), it can be ascertained that the steel cubic modules have the most important effect on the total environmental footprint for the two considered environmental parameters. The steel structural elements account for about $53 \%$ of the overall carbon footprint and for approximately $62 \%$ of the total impact on human health. At the same time, the RC slab exerts $94 \%$ of the overall negative influence on the environment in the ODP category.

Table 6. Cradle-to-Gate impact.

\begin{tabular}{cccc}
\hline Environmental Parameter & Total Impact & Steel Structure Impact & RC Slab Impact \\
\hline $\begin{array}{c}\text { Global warming potential } \\
\text { (kg CO } 2 \text {-eq.) }\end{array}$ & $30,123.13$ & $15,910.11$ & $14,213.02$ \\
$\begin{array}{c}\text { Human toxicity potential, } \\
\text { cancer effects (CTUh) }\end{array}$ & $1.09 \times 10^{-4}$ & $6.70 \times 10^{-5}$ & $4.18 \times 10^{-5}$ \\
$\begin{array}{c}\text { Ozone depletion potential } \\
\text { (kg CFC-11 eq.) }\end{array}$ & $2.84 \times 10^{-5}$ & $1.61 \times 10^{-6}$ & $2.68 \times 10^{-5}$ \\
\hline
\end{tabular}

\section{End-of-Life Assessment}

In this final part of the study, the authors have determined and interpreted the ecological benefits of the considered structure over the post-operation life cycle phase by taking into account the $\mathrm{C} 1, \mathrm{C} 2, \mathrm{C} 3$, and D life cycle modules. The analysis considered a mechanized process for the demolition of the reinforced concrete slab using a hydraulic breaker, a compact excavator, an on-site concrete crusher, and also a vibrating screen. In order to obtain a higher volume of scrap material that can be used for producing a new batch of steel-based products, the demolition of the steel module structure was considered to be completed by workers using different hand tools.

For the analyzed end-of-life (EoL) scenario, the recovery percentages of the materials consumed to build the construction under analysis are assumed to be $80 \%$ in the case of the steel cubic structure and $70 \%$ in the case of the RC slab component materials. It is also considered that in the EoL assessment the scrap steel is used for manufacturing new steel products, while the recovered concrete is used as crushed aggregates, $50 \%$ as fine aggregate and $50 \%$ as coarse aggregate (Table 7 ).

Table 7. Quantities of materials considered in the end-of-life assessment.

\begin{tabular}{cc}
\hline Material & Quantity (kg) \\
\hline SHS steel profiles & $19,315.58$ \\
Steel screws & 481.07 \\
Concrete & $33,737.90$ \\
Steel reinforcement & 1663.34 \\
Steel deck (steel sheet) & 1413.84 \\
\hline
\end{tabular}

Table 8 shows the environmental values for the end-of-life phase of the considered structure. As can be observed, the EoL scenario has a positive impact (negative values) only in the case of the GWP parameter. By comparing the global warming potential of the steel structure with that of the RC slab, it can be concluded that the recycling of the cubic modules has a negative carbon footprint, almost seven times higher than that resulting from the recycling of all the RC slab component materials. The reinforced concrete element has a lower environmental impact in terms of the HTPc and ODP parameters. 
Table 8. End-of-life environmental impact.

\begin{tabular}{cccc}
\hline Environmental Parameter & $\begin{array}{c}\text { Total EoL } \\
\text { Impact }\end{array}$ & $\begin{array}{c}\text { Recycling of the } \\
\text { Steel Structure }\end{array}$ & $\begin{array}{c}\text { Recycling of the RC } \\
\text { Slab }\end{array}$ \\
\hline $\begin{array}{c}\text { Global warming potential } \\
\text { (kg CO} \text {-eq.) }\end{array}$ & $-34,388.59$ & $-29,904.34$ & -4484.25 \\
$\begin{array}{c}\text { Human toxicity potential, } \\
\text { cancer effects (CTUh) }\end{array}$ & $2.13 \times 10^{-5}$ & $1.26 \times 10^{-5}$ & $8.17 \times 10^{-6}$ \\
$\begin{array}{c}\text { Ozone depletion potential } \\
\text { (kg CFC-11 eq.) }\end{array}$ & $1.11 \times 10^{-3}$ & $9.57 \times 10^{-4}$ & $1.49 \times 10^{-4}$ \\
\hline
\end{tabular}

\section{Discussion}

The goal of the research was to evaluate, from a cradle-to-gate with options viewpoint, the environmental impact of a structure made using a steel cubic module. The study has been completed by taking into account the following three stages of a Life Cycle Assessment analysis: the pre-operation stage, the post-operation stage, and an analysis of the overall ecological effects.

Table 9 shows the values that offer a clear description of the environmental impact of the entire structure that has been analyzed over the considered life cycle. The assessed cubic assembly has a positive effect in the case of the Global Warming Potential environmental impact parameter and a negative environmental impact in the other two considered impact categories (i.e., Human Toxicity, cancer effects, and Ozone Depletion).

Table 9. Overall impact of the considered structure.

\begin{tabular}{cccc}
\hline Environmental Parameter & Total Impact & Steel Structure Impact & RC Slab Impact \\
\hline $\begin{array}{c}\text { Global warming potential } \\
\text { (kg CO} \text {-eq.) }\end{array}$ & -4265.46 & $-13,994.23$ & 9728.77 \\
$\begin{array}{c}\text { Human toxicity potential, } \\
\text { cancer effects (CTUh) }\end{array}$ & $1.30 \times 10^{-4}$ & $7.96 \times 10^{-5}$ & $5.05 \times 10^{-5}$ \\
$\begin{array}{c}\text { Ozone depletion potential } \\
\text { (kg CFC-11 eq.) }\end{array}$ & $1.14 \times 10^{-3}$ & $9.59 \times 10^{-4}$ & $1.76 \times 10^{-4}$ \\
\hline
\end{tabular}

As observed in Figure 10 and Table 9, only the steel linear structural components of the analyzed assembly have a negative value regarding the amount of carbon dioxide emitted into the atmosphere. Therefore, it can be stated that by using the assessed products, the global phenomenon of climate change is massively influenced in a positive manner. In addition, by analysing the results it can be noticed that the steel elements of the structure are responsible for approximately $61 \%$ of the total impact over human health, expressed by using the HTPc indicator. At the same time, these structural components account for almost $85 \%$ of the overall impact on the stratospheric ozone layer, evaluated according to the ODP parameter. Therefore, the analysis shows that the reinforced concrete slab registers a significantly lower negative influence in the case of the last two considered environmental impact indicators.

Analysing the entire set of results, it can be concluded that the steel structural system can represent a viable solution for supporting present efforts that are being made at the global scale regarding the implementation of sustainable development measures in the construction sector-this despite the fact that the linear steel products have a negative effect for two of the considered environmental impact categories. This idea is supported by the massive positive influence in the case of the Global Warming indicator, which without doubt represents the most important environmental parameter, seeing that the emissions of equivalent carbon dioxide into the atmosphere represent the main reason for the temperature anomalies that are registered yearly. Another ecological benefit of the steel cubic modules is represented by the high level of recyclability of its component material, which can be translated into a significant reduction of the amount of raw materials globally 
extracted, therefore reducing the negative pressure on the natural ecosystem with respect to the Earth's capacity for renewing the global stock of natural resources.

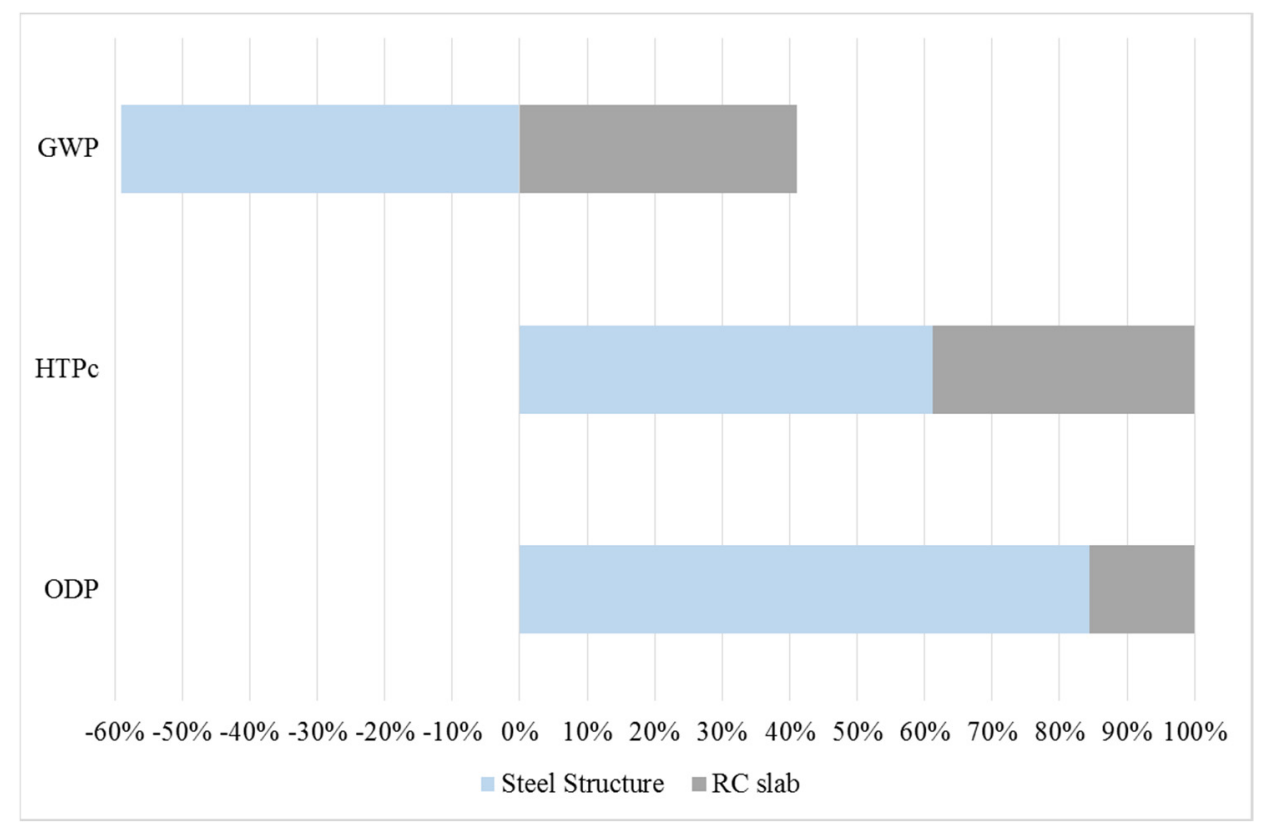

Figure 10. Total environmental influence of the considered structure.

\section{Conclusions}

As argued, the construction sector has one of the most substantial negative ecological influences at the global scale, which makes it a crucial area when it comes to achieving sustainability goals at the global level (i.e., the environmental dimension). The rapidly increasing global population phenomenon can be translated into a high demand for continuously expanding the built environment, which further leads to a greater pressure on the construction industry's global efforts to minimize its environmental impact. Considering the above, all the natural resources consumed by the activities that are specific to this sector must be handled in a more rational way. At the same time, civil engineering specialists must significantly increase the search for new innovative solutions that target both structural and environmental problems.

This study undoubtedly shows that the steel cubic modules analyzed could represent a solution for minimizing the level of environmental burdens resulting from the activities of the construction sector, especially with regard to the carbon footprint associated with the built environment. Moreover, the high degree of recyclability of steel represents another important environmental aspect of this traditional construction material that can transform this material into a more suitable solution within the current context of global sustainable development. Furthermore, the modularity of the analyzed structure can lead to a lower cost for the final users, thus also positively influencing the economic dimension of the sustainability concept. In conclusion, it can be stated that using steel as a structural material can represent a sustainable solution for the built environment. In addition, if in the near future the steel production industry will supplement its current efforts, steel could have a neutral environmental footprint.

Author Contributions: Conceptualization, S.G.M. and D.N.I.; methodology, S.G.M. and D.N.I.; software, S.G.M. and I.-R.B.; validation, D.N.I., I.-R.B., and M.L.L.; formal analysis, S.G.M. and I.-R.B.; investigation, S.G.M., D.N.I., I.-R.B., and M.L.L.; resources, S.G.M.; data curation, S.G.M., I.-R.B., and M.L.L.; writing-original draft preparation, S.G.M. and D.N.I.; writing-review and editing, I.-R.B.; visualization, I.-R.B. and M.L.L.; supervision, S.G.M.; project administration, D.N.I.; funding acquisition, S.G.M. All authors have read and agreed to the published version of the manuscript. 
Funding: This work is funded by TUIASI Internal Grants Program (GI_P9/2021), financed by the Romanian Government.

Institutional Review Board Statement: Not applicable.

Informed Consent Statement: Not applicable.

Data Availability Statement: Not applicable.

Acknowledgments: This paper was produced with the support of the TUIASI Internal Grants Program (GI_P9/2021), financed by the Romanian Government.

Conflicts of Interest: The authors declare no conflict of interest.

\section{References}

1. Global Footprint Network. Available online: https://www.overshootday.org/ (accessed on 1 September 2020).

2. Bribian, I.Z.; Capilla, A.V.; Usón, A.A. Life cycle assessment of building materials: Comparative analysis of energy and environmental impacts and evaluation of the eco-efficiency improvement potential. Build. Environ. 2011, 46, 1133-1140. [CrossRef]

3. Ding, G. Life cycle assessment (LCA) of sustainable building materials: An overview. Eco-Effic. Constr. Build. Mater. 2014, 38-62. [CrossRef]

4. Maxineasa, S.G.; Taranu, N. Environmental impact of fibre-reinforced polymer strengthening solutions of reinforced con-crete columns. Ann. Acad. Rom. Sci. 2015, 7, 41-52.

5. Maxineasa, S.G.; Taranu, N. Life cycle analysis of strengthening concrete beams with FRP. Woodhead Publ. 2018, 673-721. [CrossRef]

6. Maxineasa, S.G.; Taranu, N.; Bejan, L.; Isopescu, D.; Banu, O.M. Environmental impact of carbon fibre-reinforced polymer flexural strengthening solutions of reinforced concrete beams. Int. J. Life Cycle Assess. 2015, 20, 1343-1358. [CrossRef]

7. Maxineasa, S.G.; Entuc, I.-S.; Taranu, N.; Florenta, I.; Secu, A. Environmental performances of different timber structures for pitched roofs. J. Clean. Prod. 2018, 175, 164-175. [CrossRef]

8. Messari-Becker, L.; Bollinger, K.; Grohmann, M. Life-cycle assessment as a planning tool for sustainable buildings. In Life-Cycle and Sustainability of Civil Infrastructure Systems; Proceedings of the Third International Symposium on Life-Cycle Civil Engineering (IALCCE 2012), Vienna, Austria, 3-6 October 2012; Strauss, A., Frangopol, D.M., Bergmeister, K., Eds.; CRC Press: London, UK; pp. 1558-1562.

9. Miller, A.; Ip, K. Sustainable construction materials. In Design and Management of Sustainable Built Environments; Yao, R., Ed.; Springer: London, UK, 2013; pp. 341-358.

10. Mokhlesian, S.; Holmén, M. Business model changes and green construction processes. Constr. Manag. Econ. 2012, 30, 761-775. [CrossRef]

11. Pacheco-Torgal, F.; Labrincha, J. The future of construction materials research and the seventh UN Millennium Development Goal: A few insights. Constr. Build. Mater. 2013, 40, 729-737. [CrossRef]

12. Ramesh, T.; Prakash, R.; Shukla, K. Life cycle energy analysis of buildings: An overview. Energy Build. 2010, 42, 1592-1600. [CrossRef]

13. Romano, E.; Cascini, L.; D'Aniello, M.; Portioli, F.; Landolfo, R. A simplified multi-performance approach to life-cycle assessment of steel structures. Structures 2020, 27, 371-382. [CrossRef]

14. Vitale, P.; Spagnuolo, A.; Lubritto, C.; Arena, U. Environmental performances of residential buildings with a structure in cold formed steel or reinforced concrete. J. Clean. Prod. 2018, 189, 839-852. [CrossRef]

15. Blankendaal, T.; Schuur, P.; Voordijk, H. Reducing the environmental impact of concrete and asphalt: A scenario approach. J. Clean. Prod. 2014, 66, 27-36. [CrossRef]

16. Juan, I.A.; Müller, F.; Hack, N.; Wangler, T.; Habert, G. Potential benefits of digital fabrication for complex structures: Environmental assessment of a robotically fabricated concrete wall. J. Clean. Prod. 2017, 154, 330-340. [CrossRef]

17. Brejnrod, K.N.; Kalbar, P.; Petersen, S.; Birkved, M. The absolute environmental performance of buildings. Build. Environ. 2017, 119, 87-98. [CrossRef]

18. Iuorio, O.; Napolano, L.; Fiorino, L.; Landolfo, R. The environmental impacts of an innovative modular lightweight steel system: The Elissa case. J. Clean. Prod. 2019, 238. [CrossRef]

19. Kamali, M.; Hewage, K.; Sadiq, R. Conventional versus modular construction methods: A comparative cradle-to-gate LCA for residential buildings. Energy Build. 2019, 204, 109479. [CrossRef]

20. Lu, Y.; Le, V.H.; Song, X. Beyond Boundaries: A Global Use of Life Cycle Inventories for Construction Materials. J. Clean. Prod. 2017, 156, 876-887. [CrossRef]

21. Pacheco-Torres, R.; Roldán, J.; Gago, E.; Ordóñez, J. Assessing the relationship between urban planning options and carbon emissions at the use stage of new urbanized areas: A case study in a warm climate location. Energy Build. 2017, 136, 73-85. [CrossRef] 
22. Sathre, R.; González-García, S. Life cycle assessment (LCA) of wood-based building materials. Eco-Effic. Constr. Build. Mater. 2014, 311-337. [CrossRef]

23. Vacek, P.; Struhala, K.; Matějka, L. Life-cycle study on semi intensive green roofs. J. Clean. Prod. 2017, 154, 203-213. [CrossRef]

24. Yao, R. Sustainability in the built environment. In Design and Management of Sustainable Built Environments; Yao, R., Ed.; Springer: London, UK, 2013; pp. 1-22.

25. Zhao, D.; McCoy, A.P.; Du, J.; Agee, P.; Lu, Y. Interaction effects of building technology and resident behavior on energy consumption in residential buildings. Energy Build. 2017, 134, 223-233. [CrossRef]

26. Moynihan, M.C.; Allwood, J.M. The flow of steel into the construction sector. Resour. Conserv. Recycl. 2012, 68, 88-95. [CrossRef]

27. WSA. World Steel in Figures, World Steel Association, Brussels. 2013. Available online: https://www.worldsteel.org/steel-bytopic/statistics/World-Steel-in-Figures.html (accessed on 27 October 2021).

28. Wang, Y.; Wen, Z.; Cao, X.; Zheng, Z.; Xu, J. Environmental efficiency evaluation of China's iron and steel industry: A process-level data envelopment analysis. Sci. Total. Environ. 2019, 707, 135903. [CrossRef] [PubMed]

29. WSA. Steel Statistical Yearbook 2019, World Steel Association, Brussels. 2019. Available online: https://www.worldsteel.org/ media-centre/press-releases/2019/2019-Steel-Statistical-Yearbook-published.html (accessed on 27 October 2021).

30. Bjorn, A.; Owsianiak, M.; Laurent, A.; Olsen, S.I.; Corona, A.; Hauschild, M.Z. Scope Definition. In Life Cycle Assessment. Theory and Practice; Hauschild, M.Z., Rosen-baum, R.K., Olsen, S.I., Eds.; Springer International Publishing AG: Cham, UK, 2018; pp. $75-116$.

31. Estrada, H.; Borja, D.H.; Lee, L. Sustainability in infrastructure design. In Fiber Reinforced Polymer (FRP) Composites for Infrastructure Applications; Jain, R., Lee, L., Eds.; Springer Science+Business Media B.V.: Dordrecht, UK, 2012; pp. $23-52$.

32. Maxineasa, S.G.; Taranu, N. Traditional building materials and fibre reinforced polymer composites. A sustainability aproach in construction sector. Bull. Polytech. Inst. Iasi Constr. Archit. Sect. 2013, LIX(LXIII), 55-68.

33. Nidheesh, P.; Kumar, M.S. An overview of environmental sustainability in cement and steel production. J. Clean. Prod. 2019, 231, 856-871. [CrossRef]

34. AISC. Structural steel: The premier green construction material. In Sustainable Manufacturing Process; American Institute of Steel Construction: Chicago, IL, USA, 2016.

35. ISO. Environmental Management_Life Cycle Assessment_Principles and Framework (ISO 14040:2006); The International Or-ganization for Standardization (ISO): Geneva, Switzerland, 2006.

36. ISO. Environmental Management_Life Cycle Assessment_Requirements and Guidelines (ISO 14044:2006); The International Organization for Standardization (ISO): Geneva, Switzerland, 2006.

37. EN. Sustainability of Construction Works-Assessment of Environmental Performance of Buildings_Calculation Method (EN 15978:2011); European Committee for Standardization: Brussels, Belgium, 2011.

38. EN. Sustainability of Construction Works-Environmental Product Declarations-Core Rules for the Product Category of Construction Products (EN 15804:2012+A1:2013); European Committee for Standardization: Brussels, Belgium, 2013.

39. Isopescu, D.; Neculai, O.; Maxineasa, S.G. Report on Steel Cubic Module Structure Used for Prefabricated Constructions (In Romanian); "Gheorghe Asachi" Technical University of Iasi, Faculty of Civil Engineering and Building Services: Iasi, Rumania, 2016.

40. Isopescu, D.N.; Maxineasa, S.G.; Neculai, O. Thermal analysis of a structural solution for sustainable, modular and prefabri-cated buildings. Iop Conf. Ser. Mater. Sci. Eng. 2017, 209. [CrossRef]

41. European Commission-Joint Research Centre-Institute for Environment and Sustainability. International Reference Life Cycle Data System (ILCD) Handbook-Recommendations for Life Cycle Impact Assessment in the European context, EUR 24571 EN; Publications Office of the European Unio: Luxemburg, Luxemburg, 2011.

42. L 124. Commission Recommendation of 9 April 2013 on the use of common methods to measure and communicate the life cycle environmental performance of products and organisations (2013/179/EU); Official Journal of the European Union, Publica-tions Office of the European Union: Luxemburg, Luxemburg, 2013. 